OPEN ACCESS

Edited by:

Lei Xi,

Virginia Commonwealth University,

United States

Reviewed by:

Mohammed A. Nayeem,

West Virginia University, United States

Narasimham L. Parinandi,

The Ohio State University,

United States

*Correspondence.

Poonamjot Deol

pdeol001@gmail.com

Specialty section:

This article was submitted to

Translational Pharmacology,

a section of the journal

Frontiers in Pharmacology

Received: 07 February 2019

Accepted: 06 May 2019

Published: 29 May 2019

Citation:

Deol P, Yang J, Morisseau C Hammock BD and Sladek FM (2019) Dimethyl Sulfoxide Decreases Levels

of Oxylipin Diols in Mouse Liver.

Front. Pharmacol. 10:580.

doi: 10.3389/fphar.2019.00580

\section{Dimethyl Sulfoxide Decreases Levels of Oxylipin Diols in Mouse Liver}

\author{
Poonamjot Deol'1*, Jun Yang'2, Christophe Morisseau², Bruce D. Hammock² and \\ Frances M. Sladek ${ }^{1}$
}

${ }^{1}$ Department of Molecular, Cell and Systems Biology, University of California, Riverside, Riverside, CA, United States, ${ }^{2}$ Department of Entomology and Nematology and UCD Comprehensive Cancer Center, University of California, Davis, Davis, CA, United States

Dimethylsulfoxide (DMSO) is widely used as a solvent and cryopreservative in laboratories and considered to have many beneficial health effects in humans. Oxylipins are a class of biologically active metabolites of polyunsaturated fatty acids (PUFAs) that have been linked to a number of diseases. In this study, we investigated the effect of DMSO on oxylipin levels in mouse liver. Liver tissue from male mice (C57BI6/N) that were either untreated or injected with 1\% DMSO at 18 weeks of age was analyzed for oxylipin levels using ultrahigh performance liquid chromatography tandem mass spectrometry (UPLC-MS/MS). A decrease in oxylipin diols from linoleic acid (LA, C18:2n6), alphalinolenic acid (ALA, C18:3n3) and docosahexeanoic acid (DHA, C22:6n3) was observed $2 \mathrm{~h}$ after injection with DMSO. In contrast, DMSO had no effect on the epoxide precursors or other oxylipins including those derived from arachidonic acid (C20:4n6) or eicosapentaenoic acid (EPA, C20:5n3). It also did not significantly affect the diol:epoxide ratio, suggesting a pathway distinct from, and potentially complementary to, soluble epoxide hydrolase inhibitors (sEHI). Since oxylipins have been associated with a wide array of pathological conditions, from arthritis pain to obesity, our results suggest one potential mechanism underlying the apparent beneficial health effects of DMSO. They also indicate that caution should be used in the interpretation of results using DMSO as a vehicle in animal experiments.

Keywords: DMSO, antioxidant, inflammation, pain, arthritis, obesity, oxylipins, diols

\section{INTRODUCTION}

Dimethyl sulfoxide [DMSO, $\left(\mathrm{CH}_{3}\right)_{2} \mathrm{SO}$ ] is a polar aprotic compound with a high affinity for water (Brayton, 1986). It is commonly used as a solvent in biological experiments because it has low toxicity, can solubilize both polar and non-polar substances and can readily penetrate hydrophobic barriers such as the plasma membrane. These properties make it an ideal vehicle for both in vivo and in vitro experiments, especially for pharmacologic compounds that act on an intracellular level (Brayton, 1986).

Dimethyl sulfoxide has been reported to have therapeutic effects on a number of ailments including bacterial infections (Guo et al., 2016), dermatologic conditions (Lishner et al., 1985), chronic prostatitis (Shirley et al., 1978), gastrointestinal disorders (Salim, 1991, 1992a,b), pulmonary fibrosis and amyloidosis (Pepin and Langner, 1985; Iwasaki et al., 1994) arthritis (Elisia et al., 2016) and pain (Kingery, 1997; Kelava et al., 2011; Kumar et al., 2011; Rawls et al., 2017). 
Hepatoprotective effects of DMSO under various conditions of liver injury or hepatotoxicity have also been well documented (Siegers, 1978; Park et al., 1988; Achudume, 1991; Lind et al., 2000; Sahin et al., 2004). Although the physiological and pharmacological mechanisms underlying the beneficial health effects of DMSO are not fully known, they have been proposed to include its ability to increase blood flow to organs, decrease recruitment and activation of inflammatory cells and act as an antioxidant and free radical scavenger (Brayton, 1986; Beilke et al., 1987; Massion et al., 1996).

Oxylipins are biologically active, oxidized metabolites of long chain polyunsaturated fatty acids (PUFAs) that are generated by three different pathways - COX, LOX and CYP/sEH (Yang et al., 2009) (Figure 1). The third pathway consists of a twostep reaction involving the action of cytochrome P450s (CYPs) and soluble epoxide hydrolase ( $\mathrm{sEH}$ ) enzymes. This pathway first produces oxylipin epoxides and then diols from linoleic acid (LA, C18:2 n-6), alpha-linolenic acid (ALA, C18:3 n-3), arachidonic acid (AA, C20:4 n-6), eicosapentaenoic acid (EPA, C20:5 n-3) and docosahexaenoic acid (DHA, C22:6 n-3) (Moghaddam et al., 1997; Zeldin, 2001; Levick et al., 2007). Increased accumulation of oxylipin diols has been correlated with the pathogenesis of a number of pathological conditions including obesity, diabetes, depression, pain and cardiovascular disease (Gouveia-Figueira et al., 2015; Caligiuri et al., 2017; Deol et al., 2017; Hennebelle et al., 2017). Compounds that inhibit the formation of these lipid mediators, such as inhibitors of sEH (sEHI), have been shown to have therapeutic potential (Imig and Hammock, 2009; Morisseau et al., 2010; Wagner et al., 2017).

Dimethyl sulfoxide has been shown to attenuate the accumulation of lipids in the liver as well as free fatty acidinduced cellular lipotoxicity (Song et al., 2012). However, to our knowledge, the effect of DMSO on the hepatic levels of oxygenated fatty acid metabolites such as oxylipins has not been studied. Here, we investigate the effect of a single intraperitoneal injection of DMSO on the levels of approximately 60 oxylipin species in mouse liver. Our results show that DMSO lowers the levels of certain oxylipins, all of which are diols generated by the metabolism of omega- 3 and omega- 6 fatty acids LA, ALA and DHA.

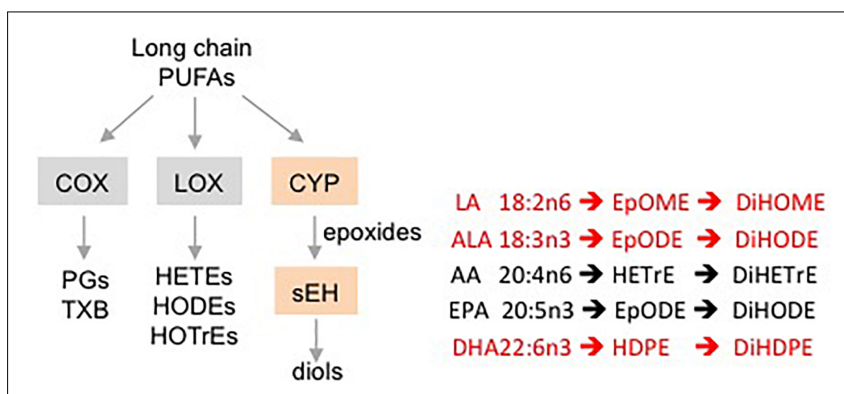

FIGURE 1 | Schematic showing different pathways for metabolizing PUFAs to oxylipins. Examples of oxylipins generated by each of the three pathways metabolizing long chain PUFAs. Shaded boxes, enzymes. Pathways affected (orange, red text) or not affected (gray, black text) by DMSO in this study.

\section{MATERIALS AND METHODS}

\section{Animals}

Care and treatment of animals were in accordance with guidelines from and approved by the University of California, Riverside Institutional Animal Care and Use Committee (AUP \#20140014). All mice had ad libitum access to regular vivarium chow (Purina Test Diet 5001, Newco Distributors, Rancho Cucamonga, CA) and water. At the end of the study, mice were sacrificed by $\mathrm{CO}_{2}$ inhalation followed by cervical dislocation, in accordance with stated NIH guidelines. C57BL/6N mice (Charles River Laboratories) were bred in-house and maintained on a 12h:12h light-dark cycle in a specific pathogen-free vivarium (SPF) with wood-chip bedding [PJ Murphy sani-chips $2.2 \mathrm{CF}$ \# 91100 (MFG 3-002)] and a cotton pad as an environmental stimulant. Pups were weaned at 3 weeks of age with three to four animals housed per cage.

\section{DMSO Treatment}

Male mice ( $\sim 18$ weeks old, $n=5$ per group) were injected intraperitoneally with $200 \mu \mathrm{l}$ of $1 \%$ DMSO (Sigma-Aldrich, catalog \# D5879) and sacrificed $2 \mathrm{~h}$ later. About $200 \mathrm{mg}$ of freshly excised liver tissue was rinsed in cold phosphate buffered saline (PBS), blotted with a Kimwipe and snap-frozen in liquid nitrogen for subsequent metabolomic analysis. Samples were also collected from a control group of age-matched mice that were not injected.

\section{Oxylipin Analysis}

Non-esterified oxylipins were extracted by solid phase extraction from liver tissue homogenates (200 $\mathrm{mg}$ ) and analyzed by ultrahigh performance liquid chromatography tandem mass spectrometry (UPLC-MS/MS) (Agilent 1200SL-AB Sciex 4000 QTrap) as described previously (Matyash et al., 2008; Yang et al., 2009; Deol et al., 2017). Analyst software v.1.4.2 was used to quantify peaks according to corresponding standard curves with their corresponding internal standards. Hepatic oxylipin concentrations are presented as $\mathrm{pmol} / \mathrm{gm}$ tissue.

\section{Statistical Analysis}

Data are presented as mean \pm standard error of mean (SEM). Statistical significance is defined as $P \leq 0.05$ using Student's $t$-test.

\section{RESULTS}

Male mice ( $\sim 18$ weeks old) were injected with $1 \%$ DMSO and sacrificed $2 \mathrm{~h}$ later. Livers were removed and analyzed for oxylipins in the COX, LOX and $\mathrm{CYP} / \mathrm{sEH}$ pathways (Figures 1, 2A). The 2-h time point was chosen to examine the short-term effects of DMSO and avoid potentially confounding factors that might be introduced by effects on gene expression. Not unexpectedly, the body weight and liver-to-body weight ratio at harvest did not differ between the control and injected groups (Figure 2B). Of the 59 oxylipin species analyzed, the DMSOinjected mice showed significantly altered levels of five species, all diols and all of which were decreased: 12,13-DiHODE, 15,16DiHODE, 12,13-DiHOME, 16,17-DiHDPE and 19,20-DiHDPE 

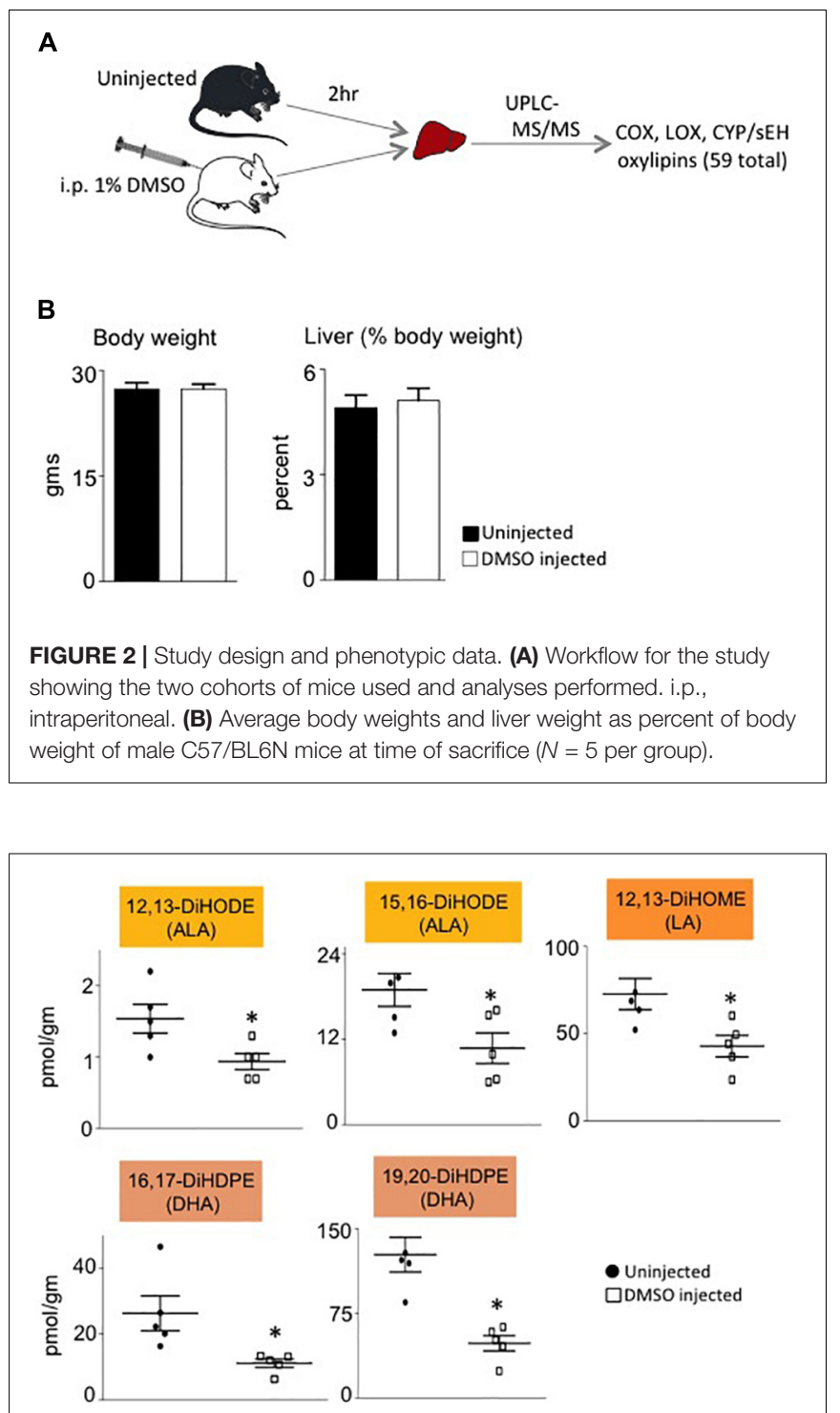

FIGURE 3 | Liver oxylipin diol levels are decreased by DMSO. Absolute levels of diols that are significantly decreased in liver of mice injected with $1 \%$ DMSO $(\square)$ compared to uninjected controls $(\bullet)$. The fatty acid from which the oxylipin was derived is shown in parentheses. $N=5$ mice per group. Data are presented as \pm SEM. *Significantly different from uninjected control, $P \leq 0.05$.

(Figure 3). In addition, levels of two diols - 14,15-DiHETrE and 13,14-DiHDPE - were also lower in the DMSO group, although the decrease did not reach statistical significance (Supplementary Table 1).

Interestingly, all of the oxylipins decreased by DMSO were in the $\mathrm{CYP} / \mathrm{sEH}$ pathway and generated by hydrolysis of epoxides of LA, ALA and DHA. In contrast, levels of the epoxide precursors of these diols were not impacted by the DMSO treatment (Figure 4A). Diol:epoxide ratios, which are a reflection of $s E H$ activity, were also not significantly different between DMSO and control, although the ratio for the DHA metabolites (DiHDPE:EpDPE) was trending toward significance (Figure 4B).

\section{DISCUSSION}

Dimethyl sulfoxide is widely used to treat numerous ailments although the underlying mechanisms remain obscure. Our results show that a single injection of DMSO can cause an immediate and pronounced decrease in oxylipin diols generated from certain omega- 3 and omega- 6 PUFAs (LA, ALA and DHA) by the $\mathrm{CYP} / \mathrm{sEH}$ pathway in mouse liver. It was proposed early on that one potential mechanism responsible for the physiological effects of DMSO was its ability to inhibit or activate various enzymes by reversibly altering their configuration (Rammler and Zaffaroni, 1967). DMSO has subsequently been shown to have a stabilizing effect on the RNA transcript levels of CYP enzymes in rat liver hepatocytes (Su and Waxman, 2004), and varying effects on CYP enzymatic activity depending on concentration, substrate and tissue or cell fraction (Chauret et al., 1998; Hickman et al., 1998; Li et al., 2010). At very high concentrations (28\% $v / v$ ) DMSO has been shown to interact with the iron center of a bacterial cytochrome P450 enzyme (Kuper et al., 2012). We did not observe an alteration in the level of the precursor epoxides, suggesting that DMSO is not acting on the CYP enzymes in our system. Similarly, the diol:epoxide ratio was not significantly altered, suggesting that sEH activity was not altered. Interestingly, oxylipin epoxide and diol levels of two other PUFAs, AA and EPA, were not affected by DMSO. Combined with the relatively short time period needed to observe these effects $(2 \mathrm{~h})$, these results suggest that DMSO acts directly, and selectively, on LA, ALA and DHA oxylipin diols (Figure 5). It remains to be determined whether chronic DMSO treatment would show a similar selective effect.

Since the decrease in hepatic oxylipin levels in our experiments does not appear to be due to a decrease in enzyme action, this suggests that, at least in the short term, DMSO is either decreasing the stability or somehow preventing the accumulation of these compounds in the liver. DMSO has been reported to have antioxidant and free-radical scavenging properties (Sanmartín-Suárez et al., 2011; Kabeya et al., 2013) Thus, it is possible that DMSO may be acting as a scavenger for these oxidized metabolites, converting them into products that are not present in our oxylipin panel. Indeed, it has been reported that DMSO, when used as a vehicle, enhances the antiinflammatory effects of rosemary and ginger (Justo et al., 2015). While the authors attributed this increase to better absorption and distribution of the compounds due to DMSO, it is possible that DMSO itself could have acted as an antioxidant, as has been shown previously (Alemón-Medina et al., 2008; Jia et al., 2010). These observations, along with the current results, indicate that caution should be employed when using DMSO as a vehicle to study the pharmacological efficacy of compounds with antioxidant potential. A direct, non-enzymatic effect of DMSO also suggests that it may have a similar effect in other tissues, and hence a broad applicability to numerous pathologies.

There are two other potential explanations for the reduced levels of the oxylipin diols. The first is that DMSO affects the level of the substrates, in this case LA, ALA and DHA. However, these fatty acids are essential (or in the case of DHA, conditionally essential), meaning that they must be derived from the diet. 


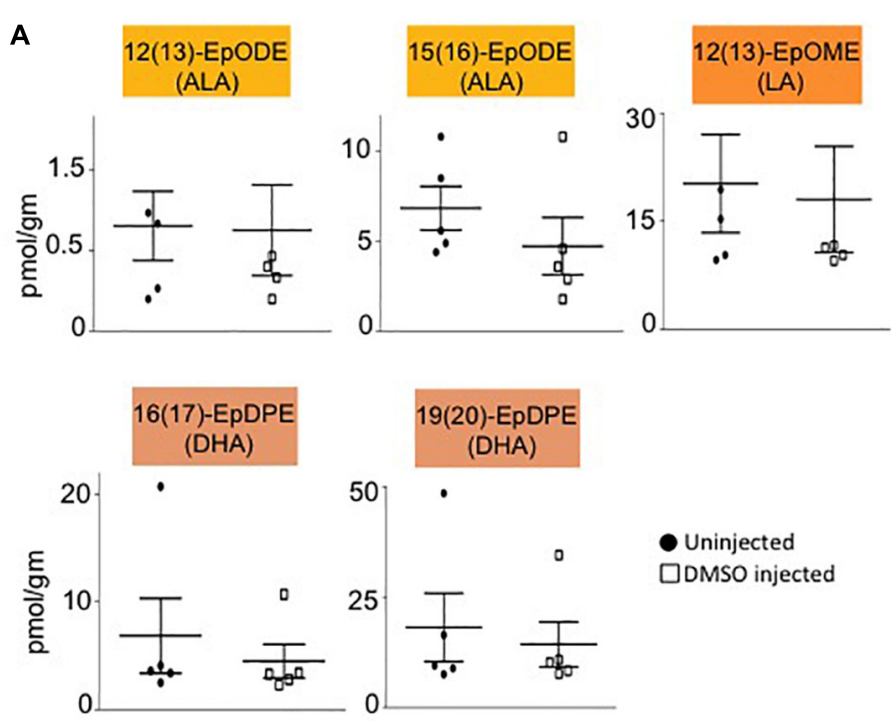

B

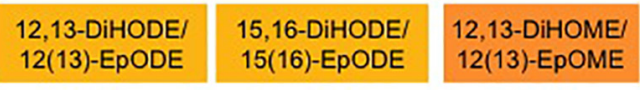

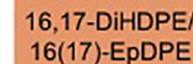

16,17-DiHDPE/
16(17)-EpDPE
19,20-DiHDPE/

19(20)-EpDPE
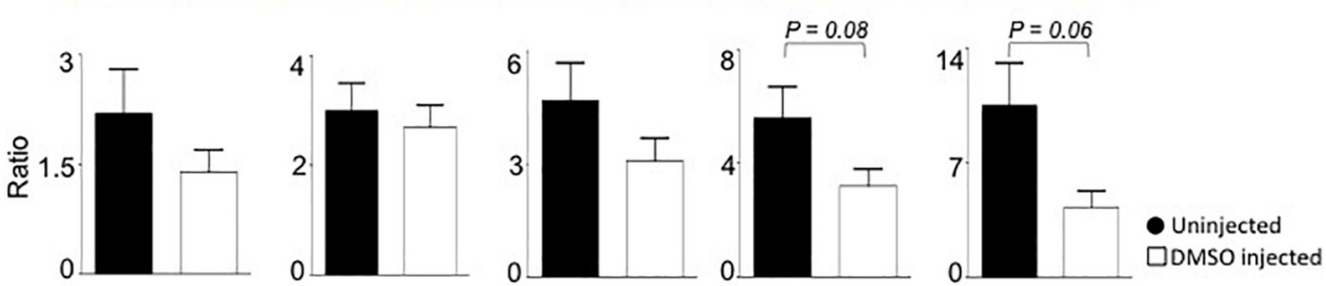

FIGURE 4 | Liver epoxide levels and diol:epoxide ratios are not affected by DMSO. (A) Absolute levels of parent epoxides of diols (shown in Figure 3) in liver of mice injected with 1\% DMSO ( $\square$ ) compared to uninjected controls $(\mathbf{O})$. The fatty acid from which the oxylipin was derived is shown in parentheses. (B) Ratio of diol:epoxide as a measure of soluble epoxide hydrolase (sEH) activity. Color coding for parental fatty acid is same as in panel (A) and Figure $\mathbf{3}$. $\mathbf{N}=5$ mice per group. Data are presented as \pm SEM. Significance is defined as $P \leq 0.05$.

Consequently, the body has robust mechanisms to maintain their levels (Tove and Smith, 1960; Lin and Conner, 1990; Lin et al., 1993; Calder, 2016) making it unlikely that within $2 \mathrm{~h}$ of injecting DMSO there would be a large decrease in the steady state levels of these essential fatty acids. Furthermore, if the levels of the parental fatty acids were decreased, one would also expect to

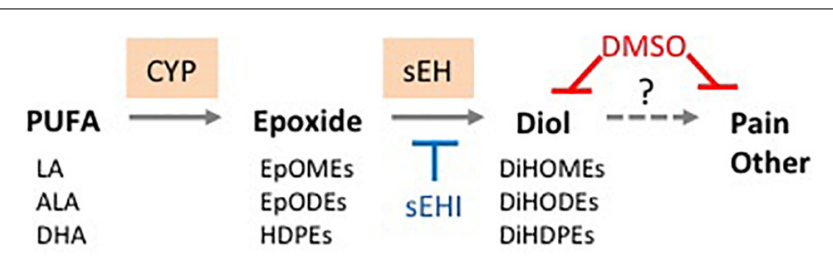

FIGURE 5 | Proposed basis for therapeutic effects of DMSO. DMSO directly reduces oxylipin diol levels in tissues and thus helps mitigate pain and other symptoms associated with diol accumulation. Solid line, known reaction; dashed line, proposed causal effect. sEHI, soluble epoxide hydrolase inhibitor. See text for details. see decreased levels of the epoxides, which is not the case. The second possibility is that the diol levels decreased not because of the DMSO but because of the stress involved with the injection. However, we did not observe such effects in mock-injected mice in previous studies (Yang et al., 2009, 2013) and it is not likely that only certain oxylipins would be so significantly changed in a general stress response.

Oxylipin diols generated from omega- 6 and omega- 3 fatty acids have been associated with a number of pathologies including obesity, diabetes, and inflammatory and cardiovascular diseases (Kalupahana et al., 2011; Grapov et al., 2012; Tourdot et al., 2014; Deol et al., 2017). Thus, it is not surprising that limiting the production of diols with $\mathrm{sEH}$ inhibitors is emerging as an important therapeutic approach in disease management (Liu et al., 2012; Bettaieb et al., 2013; Wagner et al., 2017). Decreasing oxylipin diol levels by DMSO could be used as a treatment complementary to sEHI: while inhibition of sEH would help prevent the formation of new diols, DMSO would eliminate pre-existing diols that may have accumulated prior to sEHI treatment (Figure 5). For example, DMSO has been shown to 
mitigate inflammation in arthritis (Elisia et al., 2016), a disease associated with elevated levels of oxylipins (He et al., 2015; de Visser et al., 2018; Valdes et al., 2018). In one of these studies, however, a decrease in LA-derived diols was suggested to be causal for arthritis (He et al., 2015), indicating that additional investigation is needed (Figure 5).

Another example where DMSO could play a unique therapeutic role is in reducing extreme obesity. We have shown previously that all five of the oxylipin diols decreased by DMSO in this study - 12,13-DiHODE, 15,16-DiHODE, 12,13-DiHOME, 16,17-DiHDPE and 19,20-DiHDPE - correlate positively with soybean oil-induced obesity in mice (Deol et al., 2017). Soybean oil is by far the most commonly used cooking oil in the United States and is used ubiquitously in processed foods and restaurants (Blasbalg et al., 2011; Ash, 2012). While avoiding excess soybean oil in the diet is obviously preferable to taking any sort of medication, it is intriguing to speculate that in cases of intractable obesity, a compound such as DMSO that decreases elevated levels of diols might have a therapeutic effect. For such a treatment to work, however, the DMSO would need to have more than a transient effect on diol levels. Preliminary data from our lab suggest that this might be the case for at least one of the diols (not shown).

In summary, the results reported here provide new insights into the potential health effects of DMSO, and heightens our awareness of potential complications when using it as a solvent for therapeutic compounds.

\section{ETHICS STATEMENT}

Care and treatment of animals were in accordance with guidelines from and approved by the University of California,

\section{REFERENCES}

Achudume, A. C. (1991). Effects of dimethyl sulfoxide (DMSO) on carbon (CCL4)induced hepatotoxicity in mice. Clin. Chim. Acta 200, 57-58. doi: 10.1016/ 0009-8981(91)90335-a

Alemón-Medina, R., Muñoz-Sánchez, J. L., Ruiz-Azuara, L., and Gracia-Mora, I. (2008). Casiopeína IIgly induced cytotoxicity to HeLa cells depletes the levels of reduced glutathione and is prevented by dimethyl sulfoxide. Toxicol. In Vitro 22, 710-715. doi: 10.1016/j.tiv.2007.11.011

Ash, M. (2012). Soybeans \& Oil Crops. USDA Economic Research ServiceRelated Data and Statistics. Available at: http://www.ers.usda.gov/topics/crops/ soybeans-oil-crops.aspx\#.UkIjCBZLz-Y (accessed November 1, 2016).

Beilke, M. A., Collins-Lech, C., and Sohnle, P. G. (1987). Effects of dimethyl sulfoxide on the oxidative function of human neutrophils. J. Lab. Clin. Med. 110, 91-96.

Bettaieb, A., Nagata, N., AbouBechara, D., Chahed, S., Morisseau, C., Hammock, B. D., et al. (2013). Soluble epoxide hydrolase deficiency or inhibition attenuates diet-induced endoplasmic reticulum stress in liver and adipose tissue. J. Biol. Chem. 288, 14189-14199. doi: 10.1074/jbc.M113.458414

Blasbalg, T. L., Hibbeln, J. R., Ramsden, C. E., Majchrzak, S. F., and Rawlings, R. R. (2011). Changes in consumption of omega-3 and omega- 6 fatty acids in the United States during the 20th century. Am. J. Clin. Nutr. 93, 950-962. doi: 10.3945/ajcn.110.006643

Brayton, C. F. (1986). Dimethyl sulfoxide (DMSO): a review. Cornell Vet. 76, 61-90.

Calder, P. C. (2016). Docosahexaenoic acid. Ann. Nutr. Metab. 69(Suppl. 1), 7-21.
Riverside Institutional Animal Care and Use Committee (AUP \#20140014). All mice had ad libitum access to regular vivarium chow (Purina Test Diet 5001, Newco Distributors, Rancho Cucamonga, CA) and water. At the end of the study, mice were sacrificed by $\mathrm{CO}_{2}$ inhalation followed by cervical dislocation, in accordance with stated NIH guidelines.

\section{AUTHOR CONTRIBUTIONS}

$\mathrm{PD}$ and FS conceived and designed the experiments. FS and $\mathrm{BH}$ supervised the study. PD and JY performed the experiments. PD, $\mathrm{CM}, \mathrm{BH}$, and FS analyzed and interpreted the results. PD and FS wrote the manuscript with input from the other authors.

\section{FUNDING}

This work was supported by Crohn's and Colitis Foundation of America Career Development Award (\#454808) to PD; NIH R01DK053892 and USDA National Institute of Food and Agriculture (Hatch project CA-R-NEU-5680) to FS; NIEHS R01 ES002710 to BH; NIEHS P42 ES004699 to BH and a WCMC Pilot Project from NIH U24 DK097154 to FS and BH.

\section{SUPPLEMENTARY MATERIAL}

The Supplementary Material for this article can be found online at: https://www.frontiersin.org/articles/10.3389/fphar. 2019.00580/full\#supplementary-material

Caligiuri, S. P. B., Parikh, M., Stamenkovic, A., Pierce, G. N., and Aukema, H. M. (2017). Dietary modulation of oxylipins in cardiovascular disease and aging. Am. J. Physiol. Heart Circ. Physiol. 313, H903-H918. doi: 10.1152/ajpheart. 00201.2017

Chauret, N., Gauthier, A., and Nicoll-Griffith, D. A. (1998). Effect of common organic solvents on in vitrocytochrome P450-mediated metabolic activities in human liver microsomes. Drug Metab. Dispos. 26, 1-4.

de Visser, H. M., Mastbergen, S. C., Ravipati, S., Welsing, P. M. J., Pinto, F. C., Lafeber, F. P. J. G., et al. (2018). Local and systemic inflammatory lipid profiling in a rat model of osteoarthritis with metabolic dysregulation. PLoS One 13:e0196308. doi: 10.1371/journal.pone.0196308

Deol, P., Fahrmann, J., Yang, J., Evans, J. R., Rizo, A., Grapov, D., et al. (2017). Omega-6 and omega-3 oxylipins are implicated in soybean oil-induced obesity in mice. Sci. Rep. 7:12488. doi: 10.1038/s41598-017-12624-9

Elisia, I., Nakamura, H., Lam, V., Hofs, E., Cederberg, R., Cait, J., et al. (2016). DMSO represses inflammatory cytokine production from human blood cells and reduces autoimmune arthritis. PLoS One 11:e0152538. doi: 10.1371/journal. pone. 0152538

Gouveia-Figueira, S., Nording, M. L., Gaida, J. E., Forsgren, S., Alfredson, H., and Fowler, C. J. (2015). Serum levels of oxylipins in achilles tendinopathy: an exploratory study. PLoS One 10:e0123114. doi: 10.1371/journal.pone.012 3114

Grapov, D., Adams, S. H., Pedersen, T. L., Garvey, W. T., and Newman, J. W. (2012). Type 2 diabetes associated changes in the plasma non-esterified fatty acids, oxylipins and endocannabinoids. PLoS One 7:e48852. doi: 10.1371/ journal.pone.0048852 
Guo, Q., Wu, Q., Bai, D., Liu, Y., Chen, L., Jin, S., et al. (2016). Potential use of dimethyl sulfoxide in treatment of infections caused by Pseudomonas aeruginosa. Antimicrob. Agents Chemother. 60, 7159-7169.

He, M., van Wijk, E., Berger, R., Wang, M., Strassburg, K., Schoeman, J. C., et al. (2015). Collagen induced arthritis in DBA/1J mice associates with oxylipin changes in plasma. Mediat. Inflamm. 2015:543541. doi: 10.1155/2015/543541

Hennebelle, M., Otoki, Y., Yang, J., Hammock, B. D., Levitt, A. J., Taha, A. Y., et al. (2017). Altered soluble epoxide hydrolase-derived oxylipins in patients with seasonal major depression: an exploratory study. Psychiatry Res. 252, 94-101. doi: 10.1016/j.psychres.2017.02.056

Hickman, D., Wang, J. P., Wang, Y., and Unadkat, J. D. (1998). Evaluation of the selectivity of In vitro probes and suitability of organic solvents for the measurement of human cytochrome P450 monooxygenase activities. Drug Metab. Dispos. 26, 207-215.

Imig, J. D., and Hammock, B. D. (2009). Soluble epoxide hydrolase as a therapeutic target for cardiovascular diseases. Nat. Rev. Drug Discov. 8, 794-805. doi: 10. $1038 / \mathrm{nrd} 2875$

Iwasaki, T., Hamano, T., Aizawa, K., Kobayashi, K., and Kakishita, E. (1994). A case of pulmonary amyloidosis associated with multiple myeloma successfully treated with dimethyl sulfoxide. Acta Haematol. 91, 91-94. doi: 10.1159/ 000204262

Jia, Z., Zhu, H., Li, Y., and Misra, H. P. (2010). Potent inhibition of peroxynitriteinduced DNA strand breakage and hydroxyl radical formation by dimethyl sulfoxide at very low concentrations. Exp. Biol. Med. 235, 614-622. doi: 10.1258/ ebm.2010.009368

Justo, O. R., Simioni, P. U., Gabriel, D. L., Tamashiro, W. M., Rosa, Pde T. V, and Moraes, ÂM. (2015). Evaluation of in vitro anti-inflammatory effects of crude ginger and rosemary extracts obtained through supercritical $\mathrm{CO} 2$ extraction on macrophage and tumor cell line: the influence of vehicle type. BMC Complement. Altern. Med. 15:390. doi: 10.1186/s12906-015-0896-9

Kabeya, L. M., Andrade, M. F., Piatesi, F., Azzolini, A. E. C. S., Polizello, A. C. M., and Lucisano-Valim, Y. M. (2013). 3,3',5,5'-Tetramethylbenzidine in hypochlorous acid and taurine chloramine scavenging assays: interference of dimethyl sulfoxide and other vehicles. Anal. Biochem. 437, 130-132. doi: 10.1016/j.ab.2013.02.020

Kalupahana, N. S., Claycombe, K. J., and Moustaid-Moussa, N. (2011). (n-3) Fatty acids alleviate adipose tissue inflammation and insulin resistance: mechanistic insights. Adv. Nutr. 2, 304-316. doi: 10.3945/an.111.000505

Kelava, T., Ćavar, I., and Čulo, F. (2011). Biological actions of drug solvents. Period. Biol. 113, 311-320.

Kingery, W. S. (1997). A critical review of controlled clinical trials for peripheral neuropathic pain and complex regional pain syndromes. Pain 73, 123-139. doi: 10.1016/s0304-3959(97)00049-3

Kumar, S., Kumar, S., Ganesamoni, R., Mandal, A. K., Prasad, S., and Singh, S. K. (2011). Dimethyl sulfoxide with lignocaine versus eutectic mixture of local anesthetics: prospective randomized study to compare the efficacy of cutaneous anesthesia in shock wave lithotripsy. Urol. Res. 39, 181-183. doi: 10.1007/s00240-010-0324-z

Kuper, J., Tee, K. L., Wilmanns, M., Roccatano, D., Schwaneberg, U., and Wong, T. S. (2012). The role of active-site Phe 87 in modulating the organic co-solvent tolerance of cytochrome P450 BM3 monooxygenase. Acta Crystallogr. Sect. F Struct. Biol. Cryst. Commun. 68, 1013-1017. doi: 10.1107/S1744309112031570

Levick, S. P., Loch, D. C., Taylor, S. M., and Janicki, J. S. (2007). Arachidonic acid metabolism as a potential mediator of cardiac fibrosis associated with inflammation. J. Immunol. 178, 641-646. doi: 10.4049/jimmunol.178.2.641

Li, D., Han, Y., Meng, X., Sun, X., Yu, Q., Li, Y., et al. (2010). Effect of regular organic solvents on cytochrome P450-mediated metabolic activities in rat liver microsomes. Drug Metab. Dispos. 38, 1922-1925. doi: 10.1124/dmd.110.033894

Lin, D. S., and Conner, W. E. (1990). Are the n-3 fatty acids from dietary fish oil deposited in the triglyceride stores of adipose tissue? Am. J. Clin. Nutr. 51, 535-539. doi: 10.1093/ajcn/51.4.535

Lin, D. S., Connor, W. E., and Spenler, C. W. (1993). Are dietary saturated, monounsaturated, and polyunsaturated fatty acids deposited to the same extent in adipose tissue of rabbits? Am. J. Clin. Nutr. 58, 174-179. doi: 10.1093/ajcn/ 58.2.174

Lind, R. C., Begay, C. K., and Gandolfi, A. J. (2000). Hepatoprotection by dimethyl sulfoxide: III. Role of inhibition of the bioactivation and covalent binding of chloroform. Toxicol. Appl. Pharmacol. 166, 145-150. doi: 10.1006/taap.2000. 8949

Lishner, M., Lang, R., Kedar, I., and Ravid, M. (1985). Treatment of diabetic perforating ulcers (Mal Perforant) with local dimethylsulfoxide. J. Am. Geriatr. Soc. 33, 41-43. doi: 10.1111/j.1532-5415.1985.tb02858.x

Liu, Y., Dang, H., Li, D., Pang, W., Hammock, B. D., and Zhu, Y. (2012). Inhibition of soluble epoxide hydrolase attenuates high-fat-diet-induced hepatic steatosis by reduced systemic inflammatory status in mice. PLoS One 7:e39165. doi: 10.1371/journal.pone.0039165

Massion, P. P., Lindén, A., Inoue, H., Mathy, M., Grattan, K. M., and Nadel, J. A. (1996). Dimethyl sulfoxide decreases interleukin-8-mediated neutrophil recruitment in the airways. Am. J. Physiol. 271, L838-L843.

Matyash, V., Liebisch, G., Kurzchalia, T. V., Shevchenko, A., and Schwudke, D. (2008). Lipid extraction by methyl-tert-butyl ether for high-throughput lipidomics. J. Lipid Res. 49, 1137-1146. doi: 10.1194/jlr.D700041-JLR200

Moghaddam, M. F., Grant, D. F., Cheek, J. M., Greene, J. F., Williamson, K. C., and Hammock, B. D. (1997). Bioactivation of leukotoxins to their toxic diols by epoxide hydrolase. Nat. Med. 3, 562-566. doi: 10.1038/nm05 97-562

Morisseau, C., Inceoglu, B., Schmelzer, K., Tsai, H.-J., Jinks, S. L., Hegedus, C. M., et al. (2010). Naturally occurring monoepoxides of eicosapentaenoic acid and docosahexaenoic acid are bioactive antihyperalgesic lipids. J. Lipid Res. 51, 3481-3490. doi: 10.1194/jlr.M006007

Park, Y., Smith, R. D., Combs, A. B., and Kehrer, J. P. (1988). Prevention of acetaminophen-induced hepatotoxicity by dimethyl sulfoxide. Toxicology 52, 165-175. doi: $10.1016 / 0300-483 \times(88) 90202-8$

Pepin, J. M., and Langner, R. O. (1985). Effects of dimethyl sulfoxide (DMSO) on bleomycin-induced pulmonary fibrosis. Biochem. Pharmacol. 34, 2386-2389. doi: 10.1016/0006-2952(85)90799-3

Rammler, D. H., and Zaffaroni, A. (1967). Biological implications of dmso based on a review of its chemical properties. Ann N. Y. Acad. Sci. 141, 13-23. doi: 10.1111/j.1749-6632.1967.tb34861.x

Rawls, W. F., Cox, L., and Rovner, E. S. (2017). Dimethyl sulfoxide (DMSO) as intravesical therapy for interstitial cystitis/bladder pain syndrome: a review. Neurourol. Urodyn. 36, 1677-1684. doi: 10.1002/nau.23204

Sahin, M., Avsar, F. M., Ozel, H., Topaloglu, S., Yilmaz, B., Pasaoglu, H., et al. (2004). The effects of dimethyl sulfoxide on liver damage caused by ischemiareperfusion. Transplant. Proc. 36, 2590-2592. doi: 10.1016/j.transproceed.2004. 09.057

Salim, A. S. (1991). Protection against stress-induced acute gastric mucosal injury by free radical scavengers. Intensive Care Med. 17, 455-460. doi: 10.1007/ bf01690766

Salim, A. S. (1992a). Oxygen-derived free-radical scavengers prolong survival in colonic cancer. Chemotherapy 38, 127-134. doi: 10.1159/000238952

Salim, A. S. (1992b). Role of oxygen-derived free radical scavengers in the management of recurrent attacks of ulcerative colitis: a new approach. J. Lab. Clin. Med. 119, 710-717.

Sanmartín-Suárez, C., Soto-Otero, R., Sánchez-Sellero, I., and Méndez-Álvarez, E. (2011). Antioxidant properties of dimethyl sulfoxide and its viability as a solvent in the evaluation of neuroprotective antioxidants. J. Pharmacol. Toxicol. Methods 63, 209-215. doi: 10.1016/j.vascn.2010.10.004

Shirley, S. W., Stewart, B. H., and Mirelman, S. (1978). Dimethyl sulfoxide in treatment of inflammatory genitourinary disorders. Urology 11, 215-220. doi: 10.1016/0090-4295(78)90118-8

Siegers, C.-P. (1978). Antidotal effects of dimethyl sulphoxide against paracetamol-, bromobenzene-, and thioacetamide-induced hepatotoxicity. J. Pharm. Pharmacol. 30, 375-377. doi: 10.1111/j.2042-7158.1978.tb13260.x

Song, Y. M., Song, S.-O., Jung, Y.-K., Kang, E.-S., Cha, B. S., Lee, H. C., et al. (2012). Dimethyl sulfoxide reduces hepatocellular lipid accumulation through autophagy induction. Autophagy 8, 1085-1097. doi: 10.4161/auto.20260

Su, T., and Waxman, D. J. (2004). Impact of dimethyl sulfoxide on expression of nuclear receptors and drug-inducible cytochromes $\mathrm{P} 450$ in primary rat hepatocytes. Arch. Biochem. Biophys. 424, 226-234. doi: 10.1016/j.abb.2004. 02.008

Tourdot, B. E., Ahmed, I., and Holinstat, M. (2014). The emerging role of oxylipins in thrombosis and diabetes. Front. Pharmacol. 4:176. doi: 10.3389/fphar.2013. 00176 
Tove, S. B., and Smith, F. H. (1960). Changes in the fatty acid composition of the depot fat of mice induced by feeding oleate and linoleate. J. Nutr. 71, 264-272. doi: $10.1093 /$ jn/71.3.264

Valdes, A. M., Ravipati, S., Pousinis, P., Menni, C., Mangino, M., Abhishek, A., et al. (2018). Omega-6 oxylipins generated by soluble epoxide hydrolase are associated with knee osteoarthritis. J. Lipid Res. 59, 1763-1770. doi: 10.1194/ jlr.P085118

Wagner, K. M., McReynolds, C. B., Schmidt, W. K., and Hammock, B. D. (2017). Soluble epoxide hydrolase as a therapeutic target for pain, inflammatory and neurodegenerative diseases. Pharmacol. Ther. 180, 62-76. doi: 10.1016/j. pharmthera.2017.06.006

Yang, J., Schmelzer, K., Georgi, K., and Hammock, B. D. (2009). Quantitative profiling method for oxylipin metabolome by liquid chromatography electrospray ionization tandem mass spectrometry. Anal. Chem. 81, 8085-8093. doi: $10.1021 /$ ac $901282 \mathrm{n}$

Yang, J., Solaimani, P., Dong, H., Hammock, B., and Hankinson, O. (2013). Treatment of mice with 2,3,7,8-Tetrachlorodibenzo-p-dioxin markedly increases the levels of a number of cytochrome P450 metabolites of omega-3 polyunsaturated fatty acids in the liver and lung. J. Toxicol. Sci. 38, 833-836. doi: $10.2131 /$ jts.38.833

Zeldin, D. C. (2001). Epoxygenase pathways of arachidonic acid metabolism. J. Biol. Chem. 276, 36059-36062. doi: 10.1074/jbc.r100030200

Conflict of Interest Statement: The authors declare that the research was conducted in the absence of any commercial or financial relationships that could be construed as a potential conflict of interest.

Copyright (c) 2019 Deol, Yang, Morisseau, Hammock and Sladek. This is an openaccess article distributed under the terms of the Creative Commons Attribution License (CC BY). The use, distribution or reproduction in other forums is permitted, provided the original author(s) and the copyright owner(s) are credited and that the original publication in this journal is cited, in accordance with accepted academic practice. No use, distribution or reproduction is permitted which does not comply with these terms. 